\title{
透過率測定による充てん構造の決定*
}

\author{
清 水 清** 矢 代 和 祐***
}

\section{Determination of Packing Structure by Permeability Measurements}

by

\author{
Kiyoshi Shimizu \\ (Hokkaido Gakugei University, Hakodate) \\ and Kazusuke Yashiro \\ (Hakodate College of Technology, Hakodate)
}

Bader ${ }^{1)}$ proposed an empirical equation (1) based on the measurements of air permeability of snow. A large portion of this report is concerned with the meaning of the parameters $a$ and $\varepsilon_{0}$ in Bader's formula.

Our purpose has been to measure the permeability of various packings and to determine whether the parameters obtained from the permeability measurements could be used to define the type of the packings.

It has been found that Eq. (1) has general application to homogeneous and heterogeneous beds of powders of various materials, sizes and shapes. The parameter $a$ for the same powders is constant not influenced by the structure of beds, and the relationship between $a$ and the mean volume-surface diameter $d$ is expressed by the Eq. (3). The parameter $\varepsilon_{0}$ of homogeneous beds is found to increase with decrease in the particle size below a critical diameter concerned with the materials and the shapes, and for the particle sizes greater than the critical diameter it is constant. The differences in the value of the constants for the different powders appear to depend chiefly on the particle shape. For mixtures of powders of two or three different sizes $\varepsilon_{0}$ is smaller than that for onecomponent systems. For the beds with aggregates in it $\varepsilon_{0}$ is smaller than that for the homogeneous beds, and for the beds in which two layers of different porosities are piled up $\varepsilon_{0}$ is greater than that for the homogeneous beds.

(Received May 31, 1965)

\section{1 緒 言}

粉体風の透過率に影響する層構造の一次因子は，粒 子の大きさ，形および空隙率であり，二次因子は粉体 層内にわけるそれらの分布である。粉体の積層は一次 因子か同じであっても，その程類および履歴によって 層棈造の二次因子が変化し透過性は著しく異なる。本 報では，二次的囯構造を有する粉体馗の透過率測定か ら得られる係数により，その風構造の型を推定するた めに，積雪䂪に関するBaderらの透過式の一般性を検 討したが，定性的には比較可能な絬果を得たので報告 する。

$$
2 \text { 実験 法 }
$$

微粉の透過率は水渡, 荒川らの粉体比表面程測定装 置により，粗粉の透過率は水を用いた液体透過装置に より测定した，武料の粒徍は光学顕微鏡による粒子の

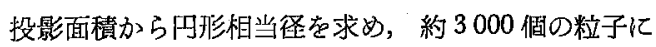
ついて体面皘平均昸 $d \mathrm{~cm}$ を定めた。試料のうち，粉

* 原稿受理 㽞和40邱 5 月 31 日

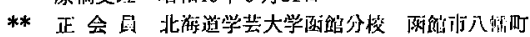

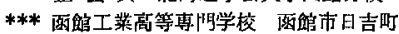

砕ガラスは鋭い跙開面を有する角型，砂は丸みのある 角型，炭酸カルシウムおよびアルミナは凹凸やしわの 多い丸型である。試料の分級は，粗粉を島津標準子る いで，微粉は Roller 型の水ひ法で行なった．温度の

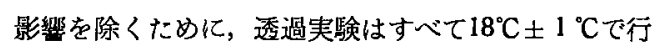
なった。

\section{Bader の透過式}

粒度のよくそろった均質な砂層の透過率 $k$ と空㮐率 モの関係を Fig. 1 の曲線 1 亿示した。 粉体層の構造 之透過率の関係は，一般に Kozeny-Carman の透過 式で表わされるが，均質な粉体風であっても空览率の 広い轮囲にわたっては成立しない．Fig. 1 の曲楾 2 は曲線 1 透過率を Kozeny-Carman の空陌率関数 $\varepsilon^{3} /(1-\varepsilon)^{2}$ の関数として示したものであるが， $\varepsilon$ か約 0.5 より大きくなると直線関係からはずれる. Bader らは，䝳雪圈の透過率 $K$ に対して

$$
K=a \frac{\varepsilon_{0} \varepsilon_{a v}}{\varepsilon_{0}-\varepsilon_{a v}}
$$

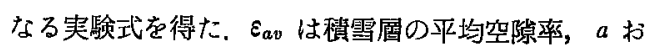
よび $\varepsilon_{0}$ は䆅雪の種類，履歴，粒度，粒形等によって 


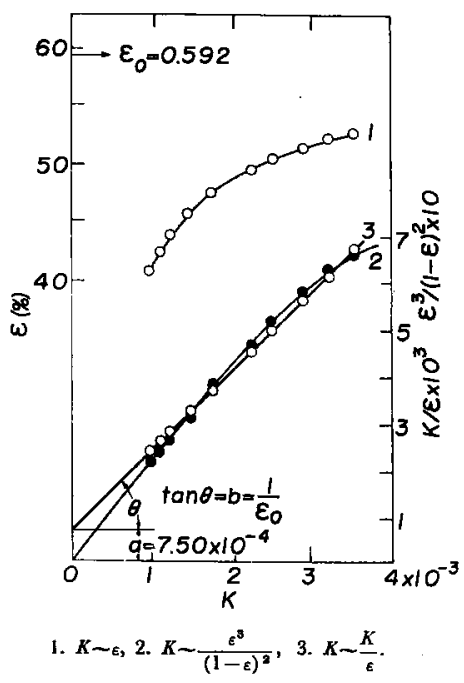

Fig. 1. Relation between permeability and porosity of sand (particle diameter $=0.638$ $\mathrm{mm}$ ).

定まる定数であるが，その物理的意味は明らかにされ ていない（1)式を変形すると

$$
\frac{K}{\varepsilon}=a+\frac{1}{\varepsilon_{0}} K
$$

となる．Fig. 1 の曲線 1 を(2)式の関係で示すと直線 3 となり，空隍率の全螌囲にわたり直線性はきわめて よい．これから $a お よ ひ ゙ \varepsilon_{0}$ は容易に定まる．実験式で あるからその近似性がよいの位当然であるが，(1)式に 合まれる係数 $a$ および $\varepsilon_{0}$ の決定がきわめて容易である から，とれらの係数と粉体層の構造との関係が明らか になればきわすて有用であると思われる。

\section{4 実験結 果}

\section{$4 \cdot 1$ 一次因子と $\varepsilon_{0}$ および $a$ の関係}

Bader の式は積雪に対して求められたものであるか ら，その一般性を検討するために種々の粉体を用いて 均質な粉体㹿の透過率を測定し(2)式の関係を Fig. 2 および Fig. 3 亿示した。砂は丸みのある角型，粉碎 ガラスは鋭い壁開面のある角型, アルミナ, 炭酸カル シウムは凹凸の多い丸型である。いずれもよい直線性 を示し，(1)式は粉体の種類によらず均質な粉体圆に対

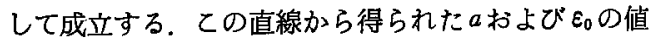
は Table I に示したが，数加ら数mmの粒径範囲 にわたって用いうる。.また，Carman の測定值から再 計算して同様の関係を Fig. 4 亿示した，特に形状の 異常な試料においてもよく適合するてとがわかる。て れらの直線から得られた $a$ および $\varepsilon_{0}$ の值は Table II に示した。

ガラス球，粉保ガラスおよび砂をふるい分けして， 粒径による $a$ 朽よび $\varepsilon_{0}$ の変化を求みた，Fig. 5 には 粒烽 $d \mathrm{~cm}$ と $\varepsilon_{0}$ の関係を示した. Table I, II および

炤和 40 年 9 月

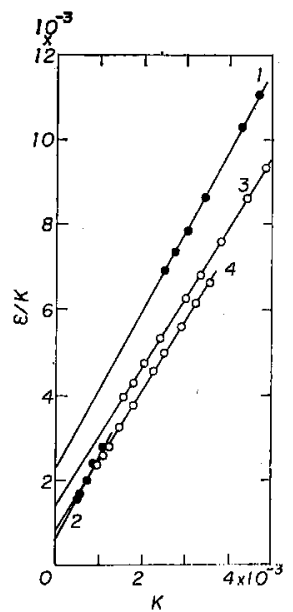

1. Glass spheres No. 1, 2. Glass spheres No. 2, 3. Sand No. 3, 4. Sand No. 4.

Fig. 2. Relation between permeability and porosity of homogeneous bed.

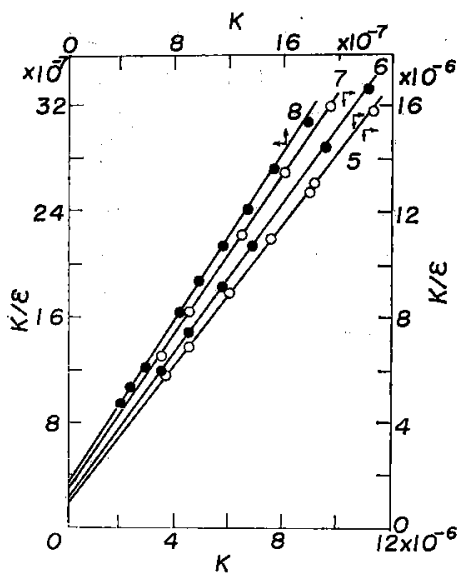

5. Alumina No. 5, 6. Calcium Carbonate No. 6 ,

7. Crushed glass No. 7, 8. Zine spheres No. 8.

Fig. 3. Relation between permeability and porosity of homogeneous bed.

Table I. Experimental values for $a$ and $\varepsilon_{0}$ of homogeneous bed.

\begin{tabular}{c|l|c|c|c}
\hline $\begin{array}{c}\text { Sample } \\
\text { No. }\end{array}$ & Materials of bed & $\begin{array}{c}\text { Diameter } \\
d(\mathrm{~cm})\end{array}$ & $a$ & $\varepsilon_{0}$ \\
\hline 1 & Glass spheres & $6.83 \times 10^{-8}$ & $2.25 \times 10^{-\mathrm{a}}$ & 0.506 \\
2 & Glass spheres & $3.69 \times 10^{-8}$ & $6.10 \times 10^{-\triangleleft}$ & 0.503 \\
3 & Sand & $8.11 \times 10^{-2}$ & $1.33 \times 10^{-8}$ & 0.597 \\
4 & Sand & $7.02 \times 10^{-2}$ & $9.50 \times 10^{-4}$ & 0.592 \\
5 & Alumina & $6.66 \times 10^{-8}$ & $0.99 \times 10^{-\mathrm{a}}$ & 0.769 \\
6 & Galcium carbonate & $5.13 \times 10^{-8}$ & $1.12 \times 10^{-8}$ & 0.717 \\
7 & Crushed glass & $4.45 \times 10^{-8}$ & $1.34 \times 10^{-\mathrm{a}}$ & 0.670 \\
8 & Zinc spheres & $2.91 \times 10^{-6}$ & $0.33 \times 10^{-\mathrm{a}}$ & 0.635 \\
\hline
\end{tabular}




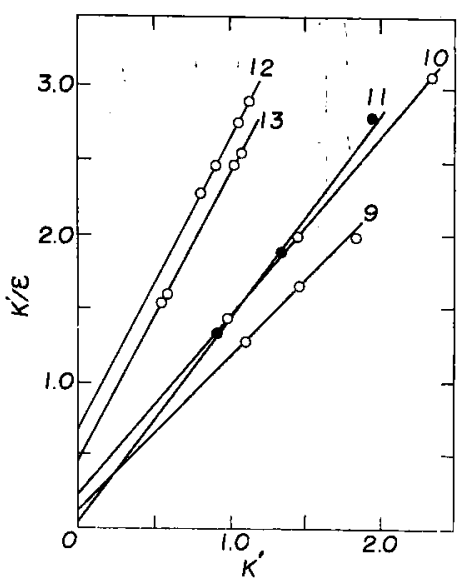

9. Lessing rings No. 9, $K^{\prime}=2 K$, 10. Steel wire crimps No. 10 , $K^{\prime}=20 K \quad 11$. Berl saddles No. 11, $K^{\prime}=K$, 12. Glass spheres No. $12, K^{\prime}=20 K \quad 13$. Sand No. $13, K^{\prime}=2 K$.

Fig. 4. Relation between permeability and porosity of homogeneous bed (Re-calculated from Carman's data).

Table II. $a$ and $\varepsilon_{0}$ of homogeneous bed (Re-calculated from Carman's data).

\begin{tabular}{r|l|c|c|c}
\hline $\begin{array}{c}\text { Sample } \\
\text { No. }\end{array}$ & \multicolumn{1}{|c|}{ Materials of bed } & $\begin{array}{c}\text { Specific } \\
\text { surface } \\
\left(\mathrm{cm}^{2} / \mathrm{cm}^{3}\right)\end{array}$ & $\boldsymbol{a}^{\prime}$ & $\varepsilon_{0}$ \\
\hline 9 & $0.6 \mathrm{~cm}$ nickel lessing rings & 59.5 & 0.063 & 0.962 \\
10 & Steel wire crimps & 126 & 0.0115 & 0.82 \\
11 & $0.6 \mathrm{~cm}$ porcelain berl saddles & 24.5 & 0.07 & 0.74 \\
12 & Glass spheres & 114 & 0.349 & 0.513 \\
13 & Sand & 89 & 0.208 & 0.518 \\
\hline
\end{tabular}

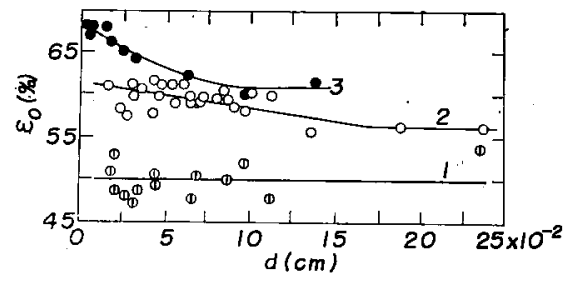

1. Glass sphercs, 2. Sand, 3. Crushed glass.

Fig. 5. Relation between $d$ and $\varepsilon_{0}$.

Fig. 5 の結果から同程度の粒徍では，粒形が球から 偏奇すると $\varepsilon_{0}$ が大きくなることがわかる，また；同 種の粉体では，粒径が減少するに伴い限界粒径以下で は $\varepsilon_{0}$ が増大しはじめる. 限界粒佳は粉体の種類によ って異なり，また，ガラス球および覀鉛球の比較から 推定すれば，球形粒子の限界粒径は非常に小さいと思 われる。

Fig. 6 には粒徍 $d$ と $a$ の関係を示した。これから，

$$
a=A d^{B}
$$

の関係が得られる. $A$ およびBは同種の粉体では定数

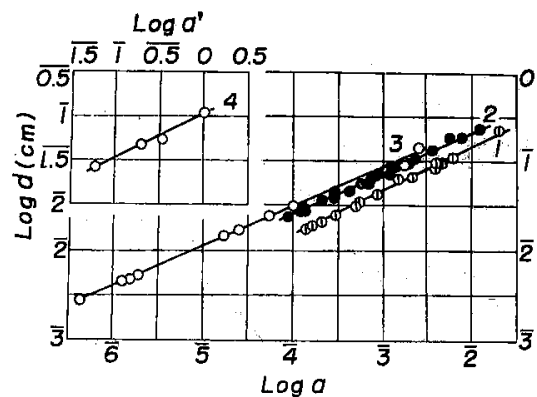

1. Glass spheres, 2. Sand, 3. Crushed glass,

4. Glass sphercs (re-calculated from Carman's date).

Fig. 6. Relation between $a$ and $d$.

Table III. Experimental values for $A$ and $B$ of homogeneous bed.

\begin{tabular}{c|l|l|l}
\hline $\begin{array}{c}\text { Sample } \\
\text { No. }\end{array}$ & Materials of bed & $A$ & $B$ \\
\hline 14 & Glass spheres & 0.449 & 2.00 \\
15 & Sand & 0.320 & 2.18 \\
16 & Crushed glass & 0.253 & 2.24 \\
17 & Glass spheres* & 107 & 2.00 \\
\hline
\end{tabular}

* Re-calcuiated from Garman's ciata.

となる、Fig. 6 から得られた $A$ およびBの値を Table III に示した，粒形か球から偏奇すると $A$ は减少し $B$ は増加する．ガラス球の $B$ は 2.00 であって Carman の式における透過率と粒茎の関係に一致する，直線 4 はガラス球についての Carman の測定値から 再計算 したもので，dおよび $a^{\prime}$ の次元は著者らと異なるにも かかわらず(3)式が成立し $B$ ままた 2.00 となる.

\section{$4 \cdot 2$ 二次因子亡 $\varepsilon_{0}$ および $a$ の関係}

粒子径の異なる同種の粉体を一定の混合率で混合し，

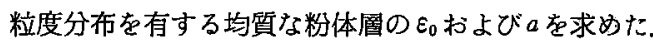
粓径差が大きと均質な分布圈を作ることが困難であ

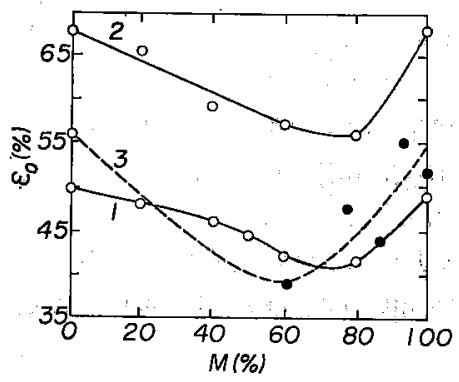

1. Glass spheres $\left(d_{1}=0.207 \mathrm{~mm}, d_{2}=0.443 \mathrm{~mm}\right)$,

2. Crushed glass $\left(d_{1}=0.145 \mathrm{~mm}, d_{2}=0.0471 \mathrm{~mm}\right)$,

3. Sand (Re-calurulated from Garman's data, $d_{1}=0.0965 \mathrm{~mm}, d_{2}=0.517 \mathrm{~mm}$ ).

Fig. 7. Relation between $\varepsilon_{0}$ and percent of large component, $M \%$, in two-component systems. 
るため広い粒径範囲を取りえなかったが(2)式の関係は よく成立した，粒昸がそれぞれ $d_{1}, d_{2}$ 友有する均質な 混合層から得られた $\varepsilon_{0}$ 之粗大粒子の混合率 $\boldsymbol{M} \%$ との 関係を Fig. 7 亿示した。曲線 3 は Carman の測定值 から再計算されたものである．原試料の $\varepsilon_{0}$ に比べて 混合層の $\varepsilon_{0}$ は小さい，粉体の種類，粒烽比等によら ず，混合率 $M \div 70 \%$ 付近で $\varepsilon_{0}$ が最小となる。 また， 混合屏の平均粒径 $d$ (これまでと同様化体面積平均径 である.）とaの関係を Fig. 8 亿示した。曲線 2 は Garman の测定值から再計算したもので，dおよび $a^{\prime}$ は著者らと異なるにもかかわらず（3)式の関係はよく 成立する. Fig. 6 およぴ Fig. 8 の結果から同種の粉 体であれば粒度分布のいかんによらず同じ $A$ および $B$ を有するととがかかる．また Fig. 7 の結果から，同 種の粉体風では同に゙平均粒径を有していても $\varepsilon_{0}$ の小 さい試料圆は粒度分布の幅が広いと見なすととができ る.

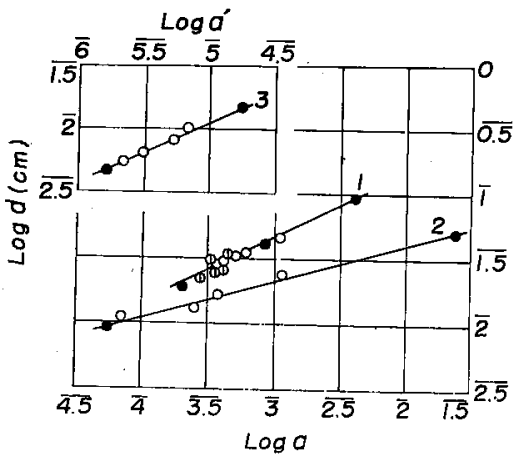

1. Glass spheres, $d_{2}=0.207 \mathrm{~mm}, d_{2}=0.443 \mathrm{~mm}, d_{3}=0.963 \mathrm{~mm}$. (1) Mixture $d_{1}$ and $d_{2}$.

O Mixture $d_{1}, d_{2}$ and $d_{8}$.

2. Sand, $d_{1}=0.0965 \mathrm{~mm}, d_{2}=0.517 \mathrm{~mm}$ (Re-calculated from O Carman's data)

3. Crushed glass, $d_{1}=0.145 \mathrm{~mm}, d_{2}=0.471 \mathrm{~mm}$ O Mixture $d_{1}$ and $d_{2}$.

Fig. 8. Relation between $a$ and $d$ for mixtures of powders of two or three different sizes.

粉体層中に団粒が生ずると一般には透過率が增大す

る.酸化第二銅および炭酸カルシウムをあらかじめ試 料筒で最密充てんした後，ふたたび取り出して任意の 大きさ，形状の団粒に粉碎し，それを原試料と混合し ながら再充てんした，その試料周（Fig. 9 の圈） の平均空隙率 $\varepsilon_{a v}$ と透過率を測定して，Fig. 9 の直線 2 および 4 亿示した。 また，炭酸カルシウムを用いて 最密充てん率を有する $1 \mathrm{~mm}^{3}$ の正六面体の団粒を作 り同様の測定を行ない，その結果を直線 6 および 7 に 示した，適当な量の団粒を含む粉体層でもすべて(2)式 は成立する。乙れから得られた $\varepsilon_{0 B}$ を均質層の $\varepsilon_{0}$ と ともに Table IV に示した。 これらの結果から団粒

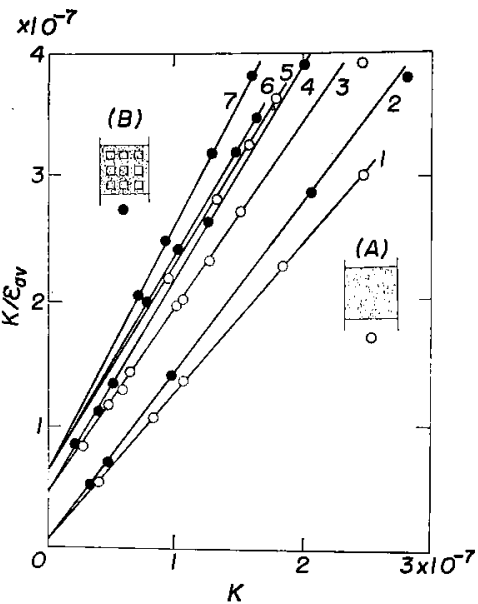

1 and 2. No. 18 cuprous oxide,

3 and 4. No. 20 calcium carbonate,

5, 6 and 7. No. 21 calcium carbonate.

Fig. 9. Relation between permeability an 4 porosity of heterogeneous bed.

Table IV. Experimental values for $a$ and $\varepsilon_{0}$ of heterogeneous bed.

\begin{tabular}{c|c|c|c|c}
\hline $\begin{array}{c}\text { Sample } \\
\text { No. }\end{array}$ & $a$ & $\begin{array}{c}\varepsilon_{0} \\
\text { (Homogeneous) }\end{array}$ & $\begin{array}{c}\varepsilon_{0 B} \\
\text { (Aggregates) }\end{array}$ & $\begin{array}{c}\varepsilon_{0 a v} \text { (I.ayers } \\
\text { of iwo } \\
\text { different } \\
\text { porosities) }\end{array}$ \\
\hline 18 & $7.50 \times 10^{-0}$ & 0.768 & 0.733 & - \\
19 & $9.05 \times 10^{-0}$ & 0.768 & - & 0.800 \\
20 & $4.7 \times 10^{-8}$ & 0.675 & 0.582 & 0.708 \\
21 & $6.16 \times 10^{-8}$ & 0.605 & $0.582(W=8 \%)$ & 0.635 \\
22 & $1.88 \times 10^{-8}$ & 0.875 & $0.515(W=67 \%)$ & 0.904 \\
\hline
\end{tabular}

の存在にかかわらず $a$ は不変であって，神は小さくな ることがわかる，空隚率の减少に伴い最密充てんでは 均質層と団粒を会む風は同一の透過率を有するととに なり，また，団粒は試料畦中で粗大粒子のような效果 を示していると思われる。

Fig. 9 の測定で用いた炭酸カルシウムの $1 \mathrm{~mm}^{3}$ 体 の団粒を 50〜 500 個の範囲内で原試料と混合し，その 透過率を測定した。試料の全重量 $W_{0}=2.70 \mathrm{~g}$ に含まれ る団粒の重量 $W^{\prime} \mathrm{g}$ の混合率 $W \%$ と $\varepsilon_{0}$ の関係が Fig. 10

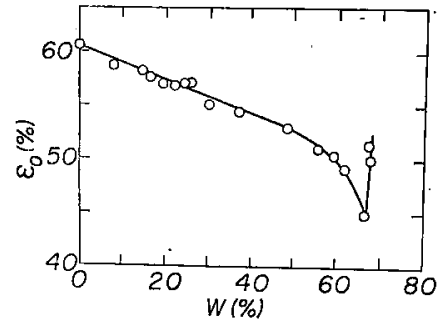

Fig. 10. Relation between $\varepsilon_{0}$ and percent of aggregate component, $W \%$, in heterogeneous bed. 
に示してある．用粒の需量すなわち偑数が增加すると $\varepsilon_{0}$ は城少しはじめ， $W$ が約 $60 \%$ 70\%付近から急激 な減少から增加に変わる，団粒がさらに增加すると四 粒に原試料が付着した状態となり透過性が不安定で再 現性のある結果が得られない。

粉体属の空隙率分布は，しばしば透過流体の流れの 方向に沿って変化している，乙れ丳試料の充てん技術 や自然の積阅の履歴に原因するてとが多い．てのよう な空榢率分布の透過性に及ばす効果は鶖視できない。 同じ原試料を用いて空陌率の異なる二圆を有する充て

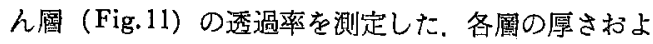

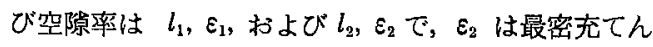
にしてある. 陚料㬝の圧縮充てんを進行させると， $l_{1}$, $\varepsilon_{1}$ が娍少し $l_{2}, \varepsilon_{2}$ は不変であると仮定して全首の平均 の空隙率 $\varepsilon_{a v}$ t定めた。 $\varepsilon_{a v}$ 之透過率 $K_{a v}$ の関係を Fig. 11 亿示した、いずれも(2)式を満足する。これか ら得られたaおよび $\varepsilon_{0 a v}$ を Table IV 亿示した，均 質な粉体阅と同じ $a$ を有するが， $\varepsilon_{0 a v}$ は均質層の $\varepsilon_{0}$ よ り大きい，全屏の平均空陌率が同じであっても，流礼

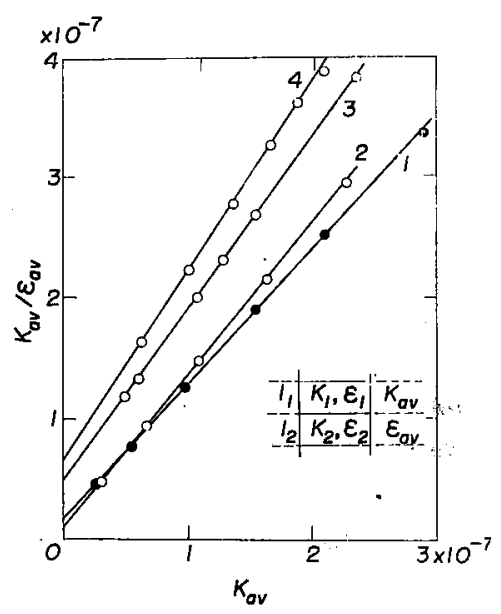

$\begin{array}{ll}\text { 1. No. } 22 \text { zine, oxide, } & \text { 2. No. } 19 \text { cuprous oxide, }\end{array}$

3. No. 20 calcium carbonate, 4. No. 21 calcium carbonate.

Fig. 11. Relation between permeability and porosity of heterogeneous bed.

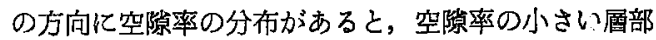
分は流体の透過を著しく妨げるものと思われる。

$$
5 \text { 結 論 }
$$

粉体圆の透過率測定から首の檏造を知ることがでさ るかいなかを検討したが，Bader の積雪に関する透過 式が一般の粉体層に対しても㐿棈造の広い範囲にわた ってよい近似性を示し，かつ透過率測定加ら得られる 係数 $a$ および $\varepsilon_{0}$ 上㬝構造の関係について次の結果を見 いだした。

（1）試料筒にとられた粉体風の空隙率を変化させて， $3 \sim 4$ 点の透過率を測定すれば，(2)式から を決定できる。

，(2）ある粉体の均質㐿についてあらかじめ $a$ および $\varepsilon_{0}$ を測定しておけば，その粉体が作る任意の粉体首に おいて， $\varepsilon_{0}$ が小さく現かれると団粒が生じており，大 きく現われると流れの方向倥陣率分布があると考兄 られる。

(3) ある粉体の均質屇についてあらかじめ(3)式の関 係を見いだしておけけは，透過率測定から求まる $a$ に上 って平均粒绎 $d$ が得られる，そのとき平均粒佳が同し であっても， $\varepsilon_{0}$ の小さい試料層は $\varepsilon_{0}$ の大きい試料㬝 に比へて粒庤分布の幅が広いか，あるいは団粒を含ん でいるととになる。

ての研究を行なうにあたり重要なで指示をいただき，

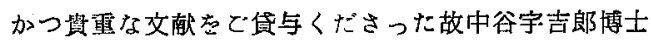
亿㳭く感謝致します。

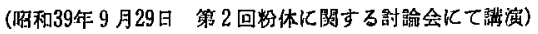

\section{参 考 文 献}

1) Bader, H., R. Haefeli, E. Bucher, J. Neher, O. Eckel, and Chr. Thamas, Beitr. z. Geolog. d. Schweiz, Geotechn. Ser., Hydrologie, Lief. 3, Bern (1939) .

2) 水渡英二，荒川正文，高橋充，工化，59，307(1956).

3) Shimizu, K., J. Gakugei Univ., 9, 19 (1958).

4) Roller, R.S., J. Phys. Chem., 45, 41 (1941).

5) Carman, P.C., J. Soc. Chem. Ind., 57, 225(1938). 